\title{
Outcome of breast cancer patients regarding obesity and complications: analysis of risk factors
}

\author{
Iuliana Pantelimon ${ }^{1,2}$, Laurentia Nicoleta Gales ${ }^{1,3}$, Maria Daniela Tanasescu ${ }^{1,4}$, \\ Irina Nita ${ }^{1,5}$, Loredana Sabina Cornelia Manolescu ${ }^{1}$, Rodica Maricela Anghel ${ }^{1,3}$ \\ 1"Carol Davila" University of Medicine and Pharmacy, Bucharest, Romania \\ ${ }^{2}$ Medical Oncology Department, "Cantacuzino" Hospital, Bucharest, Romania \\ 3 "Prof. Dr. Alexandru Trestioreanu" Institute of Oncology, Bucharest, Romania \\ ${ }^{4}$ Department of Nephrology, University Emergency Hospital, Bucharest, Romania \\ ${ }^{5}$ Medical Oncology Department, Elias University Emergency Hospital, Bucharest, Romania
}

\begin{abstract}
Introduction. Breast cancer is the leading cause of cancer death in Romania. In the context in which the treatments available for this pathology have increased curability, the identification of negative prognostic factors involved in the evolution of this disease seems essential to improve the overall survival as well as the time to disease progression.

Aim. The aim of this study is to identify the role of prognostic factors such as ki67 proliferation index, the presence of tumour estrogen receptors, HER2 overexpression, the presence of secondary determinations at diagnosis, the association of obesity and type II diabetes.

Methods. 50 patients diagnosed with breast cancer treated in the Elias University Emergency Hospital Bucharest were retrospectively followed, for which the progression was documented at the time of elaboration of this study. Thus, a database was developed in which data were entered on age, body mass index, immunohistochemical characteristics of breast tumours, the presence/absence of metastases at diagnosis and the association of type II diabetes. Statistical calculations were performed to highlight a possible correlation between obesity (quantified by measuring body mass index) and tumour aggressiveness (quantified by ki67 proliferation index) as well as statistical evaluation of potential prognostic factors that would influence time, until the disease progresses.

Results. Within this group, no correlation could be established between the presence of an increased body mass index and the value of the ki67 proliferation index $(p=0.38)$. The mean value of the body mass index for this group of unselected patients was $28.76 \pm 4.81$ (DS) most patients are therefore overweight or obese. The factors involved in the evolution of breast cancer that influenced the early progression of the disease were: the proliferation index $\operatorname{ki67}(p<0.05)$, the presence of metastases at diagnosis $(p<0.0001)$ and the association of type II diabetes $(p=0.0085)$. The value of the body mass index did not influence the time to disease progression according to statistical calculations in this group probably due to the small number of normal weight patients included $(p=0.34)$.
\end{abstract}

Keywords: breast cancer, diabetes, ki67, obesity

\section{INTRODUCTION}

Breast cancer is the leading cause of death in women worldwide and in Romania. According to data published by the IARC (International Agency on Cancer Research), 781 of the deaths due to breast cancer in postmenopausal patients are due to obesity, ranking 26th in the world (1). The data published by the WHO state that $51 \%$ of adults over the age of 20 are overweight and $19 \%$ are obese (Of these, $49.1 \%$ of women are overweight and $21.2 \%$ are obese).

In the literature there are several risk factors represented by: genetic predisposition, hormonal factors, diet and lifestyle, benign breast diseases, breast density and environmental factors (2).

\section{Corresponding authors:}

Iuliana Pantelimon 
Among these risk factors, we consider modifiable factors to be extremely important. An important example is obesity which is in turn influenced by diet, lack of physical activity as well as hormonal factors (3).

The European Guide to Breast Cancer Treatment emphasizes that the accumulation of excess fat and reduced physical activity are detrimental to the prognosis of these patients (4).

When diagnosing a patient with breast cancer, the main question that arises is related to the means that could be used to improve the prognosis of these patients, both in the short and long term. It appears that frequent imaging and biological monitoring of patients diagnosed and treated for breast cancer has not brought a benefit on overall survival (5).

What seems to have a benefit on reducing the risk of recurrence and mortality of patients with breast cancer is represented by sustained physical exertion, weight loss and avoidance of obesity, as well as decreased alcohol consumption (6).

\section{AIM}

This paper aims to identify negative prognostic factors that would influence the survival to disease progression of patients diagnosed with breast cancer. These factors could be represented by the immunohistochemical characteristics of the tumour (presence/absence of estrogen receptors), by the advanced diagnosis (presence of metastases) or by the association of other pathologies such as obesity and type II diabetes.

\section{MATERIAL AND METHODS}

\section{Data source}

The observation sheets and medical documents of 50 patients diagnosed and treated with breast cancer between January 2009 and December 2014 at the Elias University Emergency Hospital were analysed retrospectively. The study was retrospective, observational, non-randomized, on a sample of 50 patients diagnosed with breast cancer, in different oncological stages, a representative sample for a population of patients with breast cancer, investigated/treated in a centre specialized in the treatment of oncological diseases.

The target group was represented by patients diagnosed with breast cancer in the hospital and who at the time of compiling the database had remote secondary determinations.

In order to study the working hypotheses, the patients in the database were divided according to
BMI into 3 groups: normal-weight patients with BMI between 18.5 and $24.9 \mathrm{~kg} / \mathrm{m}^{2}$, overweight patients with BMI between 25 and $29.9 \mathrm{~kg} / \mathrm{m}^{2}$ and obese patients with BMI $>30 \mathrm{~kg} / \mathrm{m}^{2}$.

Patients were also divided according to the presence or absence of estrogen receptors in immunohistochemistry, according to the presence or absence of HER2 expression and according to menopausal status, respectively, premenopausal or postmenopausal patients, the presence or absence of diabetes.

Inclusion criteria:

- Patients aged 18-90 years.

- Patients under treatment or monitoring at Elias University Emergency Hospital, Medical Oncology Department, between January 2009 and December 2014.

- Patients whose disease has progressed during this period, progressively documented by imaging.

- The availability of source medical documents, which should show the information that makes up the variables studied such as: histopathological and immunohistochemical report, patient weight and height, to calculate body mass index, imaging investigation attesting the disease progression, presence/ absence of menopause, presence/absence of type II diabetes, anamneses of the oncological treatments received, results of the imaging investigations reports in which the locations of the remote secondary determinations are described.

Exclusion criteria:

- Patients for whom the information corresponding to the studied variables was not available.

- The presence of a second cancer at the same time.

- Serious diseases at the time of diagnosis.

\section{Statistical analysis}

For statistical analysis, the Ri program, version 3.6.2 (2019) was used. In addition to the standard packages, the following packages were also used:

- survival Therneau T (2015)._A Package for Survival Analysis in S_. version 2.38, <URL:https://CRAN.R-project.org, Alboukadel Kassambara and Marcin Kosinski (2018).

- survminer: Drawing Survival Curves using 'ggplot2'. R package version 0.4.3. https:// CRAN.R-project.org. 


\section{RESULTS}

The statistical indicators followed in this research are: age; body mass index (BMI); ki67 proliferation index; the presence of diabetes; immunohistochemical characteristics of the tumor (presence/absence of estrogen receptors, overexpression of HER2); time to disease progression (PFS).

These indicators shall be analysed each individual with the distribution within the group of patients studied in order to verify the hypotheses issued.

\section{Analysis of the correlations between BMI and the level of expression of ki67}

In Table 1, the Pearson $r$ index was calculated to establish a possible correlation between the body mass index (BMI) as an expression of excess adipose tissue and the ki67 proliferation index as an expression of breast cancer aggressiveness.

TABLE 1. Correlation between obesity and ki67 proliferation index (Pearson correlation coefficient)

\begin{tabular}{|l|l|}
\hline Obesity parameter & $\begin{array}{l}\text { Express ki67 } \\
\text { r Pearson }(\boldsymbol{p} \text {-value) }\end{array}$ \\
\hline BMI & $0.125(0.3844)$ \\
\hline
\end{tabular}

The data do not suggest that there is a statistically significant correlation between BMI and the level of expression of ki67 ( $p>0.05)$, see also Figure 1.

\section{Time to disease progression}

The analysis was a Kaplan-Meier type for general and menopausal analysis: yes/no, estrogen re- ceptor expression: yes/no, HER2 overexpression: yes/no, the existence of diabetes mellitus (DM): yes/no, the existence of neoplastic secondary determinations at the initial diagnosis: yes/no, for testing the survival curves on the different stratums using a log-rank test, for the interval variables (age, BMI, expression level of ki67) using a Cox regression.

The study did not include censored patients, in all patients appearing the event of interest (disease progression), the average occurrence of progression was calculated, the median occurrence of progression with 95\% CI (when possible).

Kaplan-Meier analysis and survival curve to disease progression are illustrated in Figure 2.

TABLE 2. Survival to disease progression in the studied group

\begin{tabular}{|l|l|l|c|}
\hline Strata & Average & Median & IC 95\% Median \\
\hline Whole lot & 40.98 & 16.00 & 13.00 to 29.00 \\
\hline
\end{tabular}

Survival without median progression was 16 months and median survival was 40.98 months (Table 2).

For a conclusive analysis of the main prognostic factors followed in this study, we assessed their influence on the progression without signs of disease, namely the presence/absence of estrogen receptors, HER2 status, menopausal status, the presence/absence of diabetes.

\section{Analysis of the impact regarding the presence of estrogen receptors on progression-free survival (PFS)}

Figure 3 illustrates the Kaplan-Meier survival curve as a function of the presence/absence of estrogen receptors in immunohistochemistry.

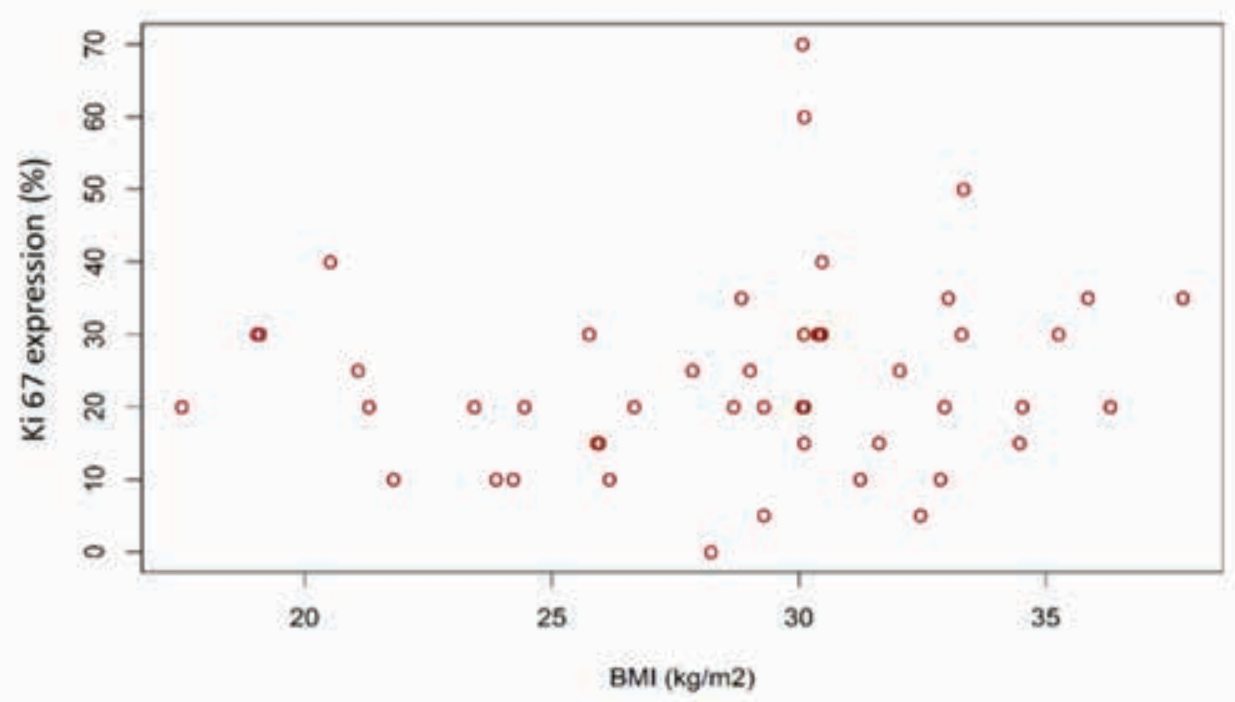

FIGURE 1. Correlation between body mass index and the value of the ki67 proliferation index 


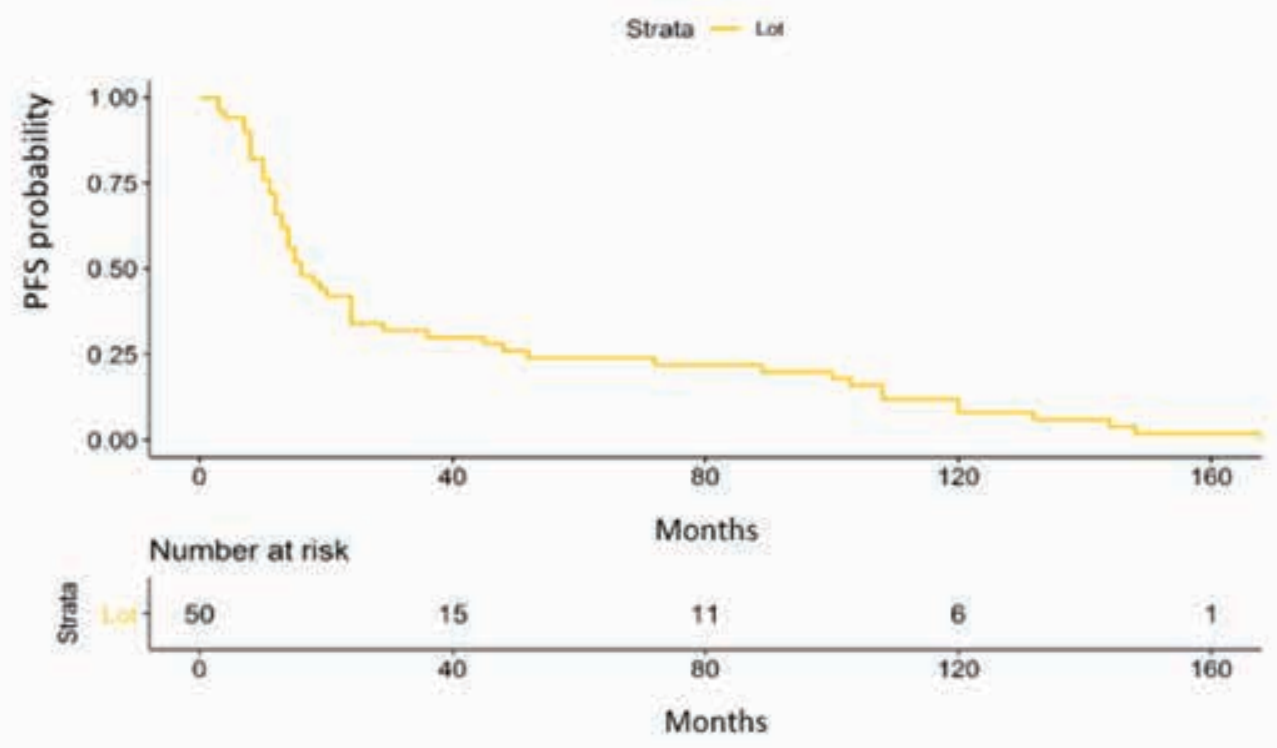

FIGURE 2. Kaplan-Meier curve of survival to disease progression

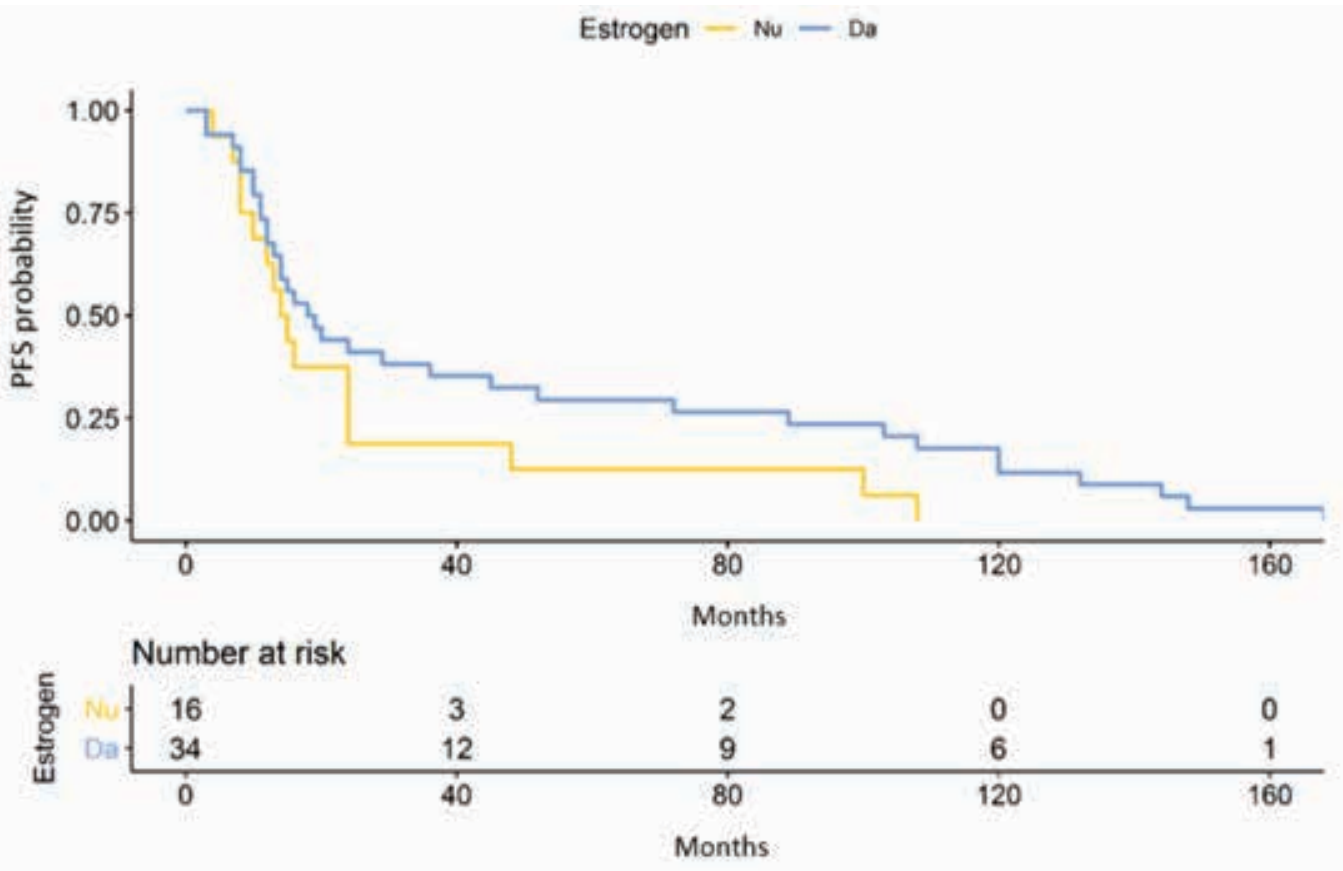

FIGURE 3. PFS survival curve as a function of estrogen receptor expression

Survival data are highlighted in Tables 3 and 4 and the log-Rank test is applied.

TABLE 3. PFS analysis as a function of estrogen receptor expression at $\mathrm{IHC}$

\begin{tabular}{|l|l|l|l|}
\hline Strata & Average & Median & IC95\% Median \\
\hline Estrogen (-) - 16 & 27.20 & 14.50 & 10.00 to 48.00 \\
\hline Estrogen (+) -34 & 47.50 & 18.50 & 14.00 to 52.00 \\
\hline
\end{tabular}

TABLE 4. Log-Rank test for patients with / without estrogen receptors

\begin{tabular}{|l|l|}
\hline Statistic $\chi^{2}$ & $p$ Value \\
\hline 2.40, 1 freedom degree & 0.1000 \\
\hline
\end{tabular}

The differences between the survival curves are marginally insignificant $(p=0.10)$, PFS seems bet- ter for estrogen receptor tumours, but the data are inconclusive. These data are not statistically significant due to the fact that the group of patients was followed for a short period of time as well as the fact that it was composed of patients who were initially both in the early and metastatic stages.

\section{Analysis of data on HER2 overexpression and the progression-free survival curve}

After assessing survival to disease progression for patients whose tumours overexpress HER2 compared to those without expression did not detect a difference, as suggested by the Kaplan Meier curve in Figure 4. By performing statistical calculations, the median survival was 17.5 months for 


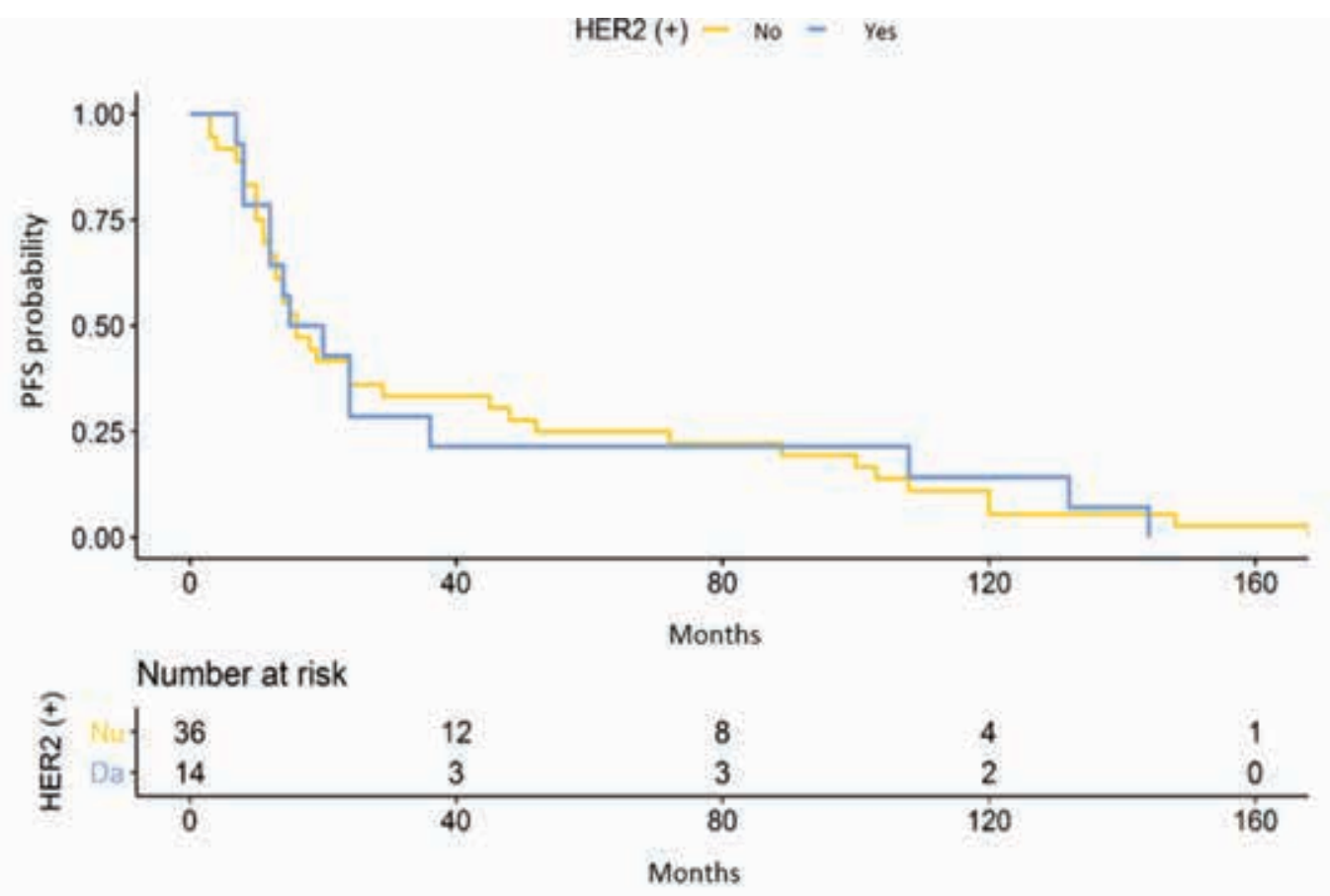

FIGURE 4. Survival curve to disease progression as a function of HER2 overexpression

HER2 positive patients compared to 16 months for HER2 negative ones. Applying the log-rank formula this difference is not statistically significant $(\mathrm{p}=1)$.

Survival analysis without disease progression according to the presence / absence of diabetes

In the context in which obesity is frequently associated with the presence of type II diabetes, a statistical analysis was performed regarding the influence of the association of diabetic pathology on the evolution of breast neoplasm given that in this group most patients were overweight or obese. The analysis of Figure 5 shows a decrease in time to disease progression for patients associated with the diagnosis of diabetes. This is also highlighted by the statistical calculations in Tables 5 and 6 . Thus, we observe an average survival of 47 months for patients who do not associate diabetes compared to 19.6 months for diabetics.

Median survival is 24 months compared to 15 months. These are statistically significant $(\mathrm{p}<0.05)$.

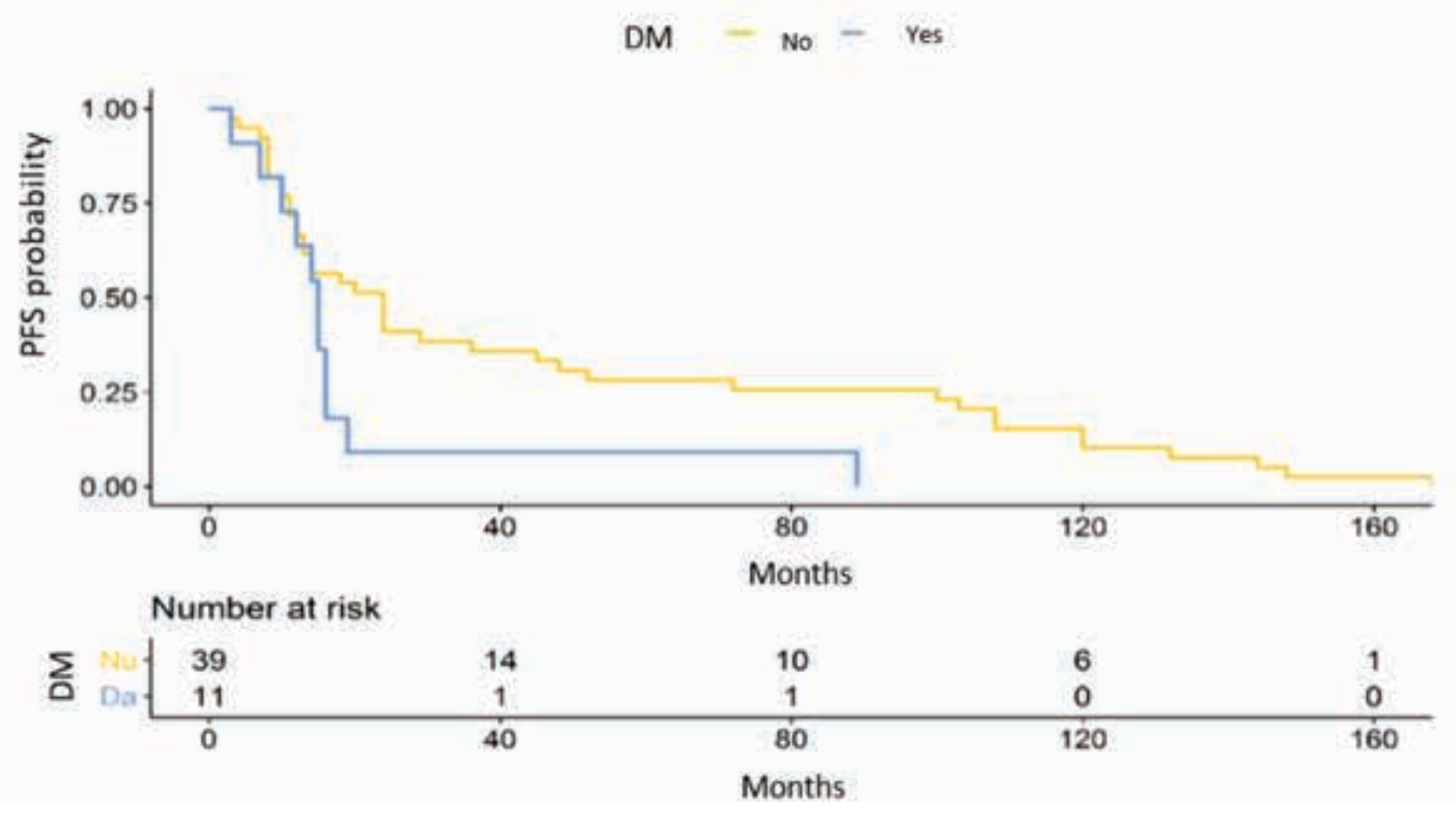

FIGURE 5. Survival curve without disease progression depending on the association of diabetes 
TABLE 5. Survival without disease progression in patients with / without associated diabetes

\begin{tabular}{|l|l|l|l|}
\hline Strata & Average & Median & IC95\% Median \\
\hline DM (-) - 39 & 47.00 & 24.00 & 13.00 to 48.00 \\
\hline DM (+) - 11 & 19.60 & 15.00 & 12.00 to N/A \\
\hline
\end{tabular}

DM- type II diabetes

TABLE 6. Log-rank test in patients with / without diabetes

\begin{tabular}{|l|c|}
\hline Statistic $\chi^{2}$ & $p$ value \\
\hline 4.30, 1 degree of freedom & 0.0400 \\
\hline
\end{tabular}

\section{Survival analysis without disease progression according to the presence/absence of metastases at initial diagnosis}

Figure 6 shows that the time to disease progression is significantly shorter for patients who had secondary determinations at diagnosis.

Patients who had metastases at the time of diagnosis have lower and median progression-free survival than patients without metastasis $(\mathrm{p}<0.01)$ statistical calculations Median survival without disease progression is 36 months for patients who did not have metastases at diagnosis compared to 14 months for those diagnosed in the metastatic stage.

To investigate the possible influence of these variables on disease-free survival, a simple Cox regression is used. Also, in order to provide more reproducible information, the influence of significant variables on the log-rank test was calculated.

The initial model was the simple one (only one independent parameter in the model).
TABLE 7. Variables that influenced the progressionfree survival of the study group

\begin{tabular}{|l|l|l|l|}
\hline Variable & Coefficient & $\mathbf{p}$ Value & HR [IC95\%] \\
\hline Age & 0.02 & 0.1620 & $1.02[0.99$ to 1.05$]$ \\
\hline Percentage ki67 & 0.03 & 0.0023 & $1.03[1.01$ to 1.05$]$ \\
\hline BMI & 0.02 & 0.3480 & $1.02[0.96$ to 1.09$]$ \\
\hline $\begin{array}{l}\text { Present } \\
\text { metastases }\end{array}$ & 1.44 & $<0.0001$ & $4.25[2.15$ to 8.38$]$ \\
\hline DM & 0.73 & 0.0433 & $2.09[1.02$ to 4.28$]$ \\
\hline
\end{tabular}

The analysis of Table 7 shows that there is an influence of the percentage of ki67 proliferation index on PFS, an increase of one percent of expression being associated with an increase in the probability of developing a disease progression earlier, an increase of $5 \%$ being associated with a $3 \%$ higher probability of faster progression $(\mathrm{p}<0.01)$; the presence of DM is associated with a probability of progression 2 times higher $(p<0.05)$. Also, the probability of developing progression earlier is 4.25 times higher in patients who had metastases at the time of diagnosis, the effect being statistically significant $(\mathrm{p}<0.01)$.

Multiple Cox regression used the variables with statistical significance in the simple analysis, the algorithm used was that of retrograde selection and the final model is shown in table 8 .

TABLE 8. Variables that influence early disease progression

\begin{tabular}{|l|l|l|l|}
\hline Variable & Coefficient & p value & HR [IC95\%] \\
\hline Percentage ki67 & 0.02 & 0.0189 & $1.02[1.01$ to 1.04] \\
\hline Present metastases & 1.52 & $<0.0001$ & $4.60[2.25$ to 9.39] \\
\hline DM & 0.99 & 0.0085 & $2.70[1.28$ to 5.67] \\
\hline
\end{tabular}

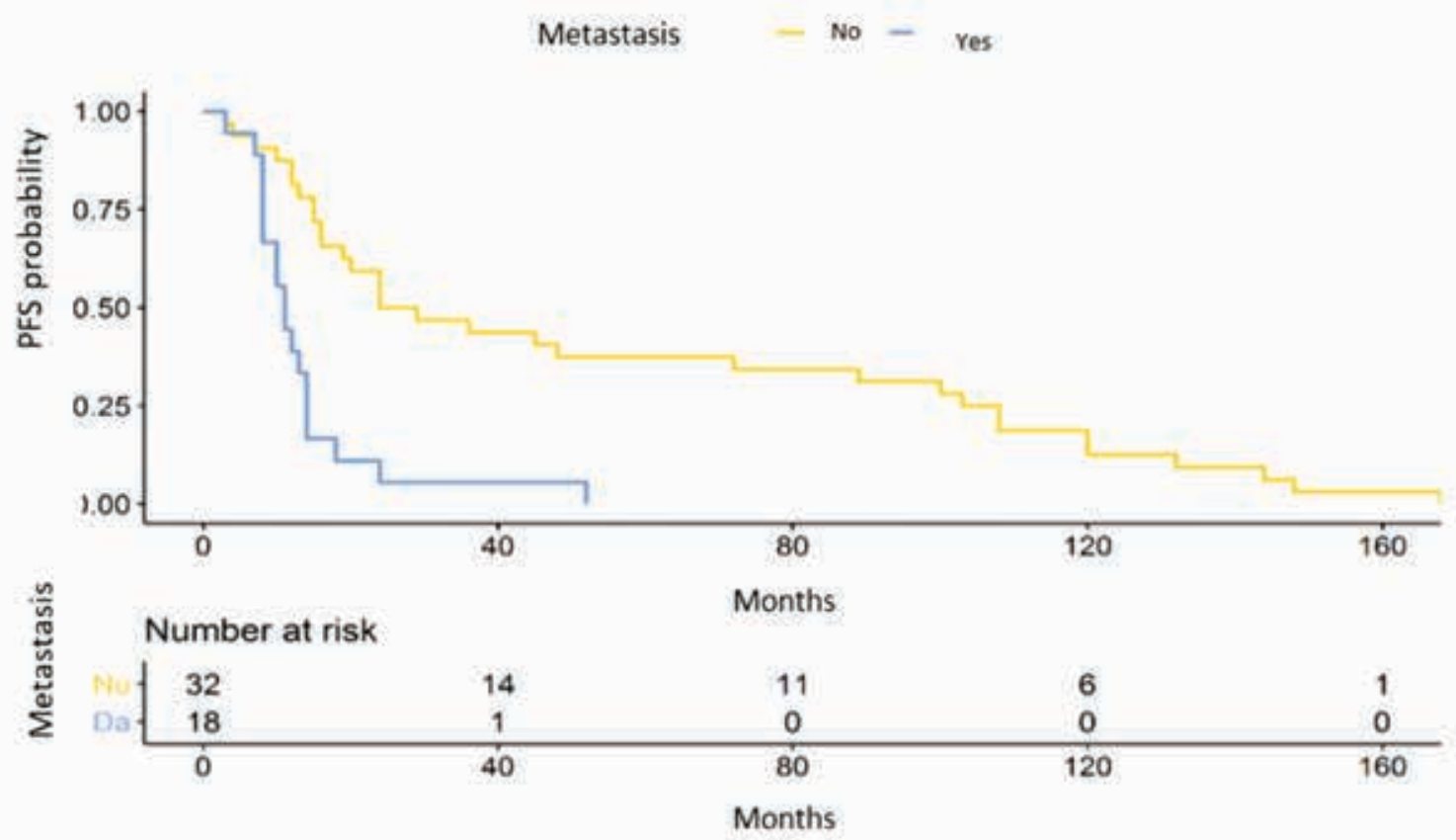

FIGURE 6. Survival without disease progression in patients with the presence/absence of metastases at diagnosis 
The independent risk factors that influence the probability of early onset of neoplasia progression are: ki67 percentage with $2 \%$ increase probability for a 5\% increase in the percentage of ki67 proliferation index ( $p<0.05)$, the existence of initial metastases with an increase of the probability of 4.6 times and the existence of diabetes with an increase of 2.7 of the probability of early progression.

\section{Descriptive analysis of the analysed batch}

Table 9 summarizes the characteristics of the studied group are in the form of mean \pm standard deviation (D.S) for continuous variables, and in the form of absolute frequency (relative frequency - percentages) for category variables.

TABLE 9. Characteristics of patients

\begin{tabular}{|c|c|c|}
\hline \multicolumn{2}{|l|}{ Variable } & Patients \\
\hline \multicolumn{2}{|l|}{ Age - Average \pm D. S } & $54.58 \pm 9.83$ \\
\hline Estrogen receptors & $\begin{array}{l}\text { No-No. (\%) } \\
\text { Yes - No. (\%) }\end{array}$ & $\begin{array}{l}16(32.00) \\
34(68.00)\end{array}$ \\
\hline \multicolumn{2}{|c|}{ ki67 percentage - Average \pm D. S } & $23.80 \pm 13.23$ \\
\hline \multicolumn{2}{|c|}{$\begin{array}{r}\text { HER2 Overexpression No - No. (\%) } \\
\text { Yes - No. (\%) }\end{array}$} & $\begin{array}{l}36(72.00) \\
14(28.00)\end{array}$ \\
\hline \multicolumn{2}{|c|}{ Progression time - Average \pm D.S } & $40.98 \pm 46.50$ \\
\hline Diabetes & $\begin{array}{l}\text { No-No. (\%) } \\
\text { Yes-No. (\%) }\end{array}$ & $\begin{array}{l}39(78.00) \\
11(22.00)\end{array}$ \\
\hline Initial metastases & $\begin{array}{l}\text { No- No. (\%) } \\
\text { Yes-No. (\%) }\end{array}$ & $\begin{array}{l}32(64.00) \\
18(36.00)\end{array}$ \\
\hline \multicolumn{2}{|l|}{ BMI - Average \pm D. S } & $28.76 \pm 4.81$ \\
\hline
\end{tabular}

\section{DISCUSSIONS}

This study aimed to identify some prognostic factors involved in the evolution of breast cancer and the possible implications caused by the presence of excess adipose tissue. All the patients included in this study were screened for cervical cancer and viral diseases such as hepatitis B, C or HIV. We consider this aspect very important for therapeutic compliance (7-13).

Obesity has shown a definite negative influence on the evolution of breast cancer in the postmenopausal period and most likely in the premenopausal period, according to recent literature. Given this context, we tried to demonstrate an association between obesity and the development of breast tumors with a higher degree of aggression, expressed by a proliferation index increased in percentage.

In order to establish a correlation between the presence of obesity and the aggressiveness of the breast neoplasm, a Pearson correlation index was calculated between the value of the body mass index and the value of the proliferation index ki67.

A study by Inwald E.C. and collaborators have shown that the ki67 proliferation index has predic- tive value in terms of overall survival and disease-free survival $(14,15)$. However, there is a study published in 2018 that highlights the fact that, in obese patients, intrinsic subtypes with favorable evolution predominate (16).

In this group, no correlation could be established between the presence of an increased body mass index and the value of the ki67 proliferation index. This correlation may not be statistically significant in the context of a small group of patients and the fact that most of the patients included in this group were overweight or obese.

A very valuable tool for assessing prognosis, prognostic factors as well as response to treatment is survival without disease progression.

Survival without progression of the disease is 40.98 months in the context of a mixed group, in terms of disease stage.

According to the Breast Cancer Diagnosis and Treatment Guide (ESMO), survival at 10 years is on average $70 \%$, the recurrence rate is higher in the first 2 years after which it decreases to a recurrence risk of $2-5 \%$ per year for treated localized breast cancer (17). In the case of metastatic breast cancer, the median overall survival is approximately 3 years and the 5 -year survival is $25 \%$ (18). Because the group was mixed in this study, consisting of patients in different stages, all of whom progressed, it is difficult to compare with data from the literature.

The status of estrogen receptors in immunohistochemistry is validated as an important prognostic factor for survival. It is known from the literature that patients with breast cancer and estrogen receptors may recur even 20 years after diagnosis (19). Another aspect is represented by the fact that in the case of breast tumors with estrogen receptors present, several types of treatments are available with increased effectiveness compared to other histological subtypes, the prognosis of these tumors being improved.

Thus, in this group, the impact of estrogen receptor expression on the time to disease progression was evaluated. Although apparently survival without disease progression is longer for patients with tumors expressing these receptors, this difference was not statistically significant $(p=0.1)$. These data have no statistical significance due to the fact that the group of patients was followed for a short period of time as well as the fact that it was composed of patients initially in both the early and metastatic stages.

HER 2 amplification is present in $20-30 \%$ of patients diagnosed with breast cancer. The main 
result of HER2 overexpression is the acceleration of tumor cell growth and proliferation. HER 2/neu overexpression is considered a sign of tumor aggression, but with the discovery of anti-Her agents, the prognosis of these patients improved with a halving of the recurrence rate, which means a $10 \%$ benefit for 3-year survival without signs of disease. a 3\% increase in overall survival at 3 years (20).

Starting from the premise that HER2 overexpression in patients with breast cancer could negatively influence we evaluated the survival to disease progression in the studied group. Median survival without disease progression was 16 months for HER2-negative patients compared to 17.5 months for HER2-positive patients. The differences were of no statistical significance $(p=1)$ probably in the context of the development of targeted anti- HER 2 treatments with increased efficacy that led to increased survival of patients with HER 2 overexpressed tumors.

Insulin, one of the key hormones involved in the evolution of glucose intolerance and diabetes, also plays an important role in intracellular signaling and uncontrolled proliferation of neoplastic disease. Because this hormone interacts with multiple intra- and intercellular signaling pathways, after binding to its receptor, insulin, in addition to its role in energy metabolism, has an important function in transmitting growth and proliferation signals through interaction with mitogen-activated protein kinase (MAPK) (21). There are studies that suggest that high serum fasting insulin levels in patients diagnosed with breast cancer cause an unfavorable prognosis for them (22).

Based on these data from the literature and from the fact that most patients in this group were overweight or obese, the role of the association of type II diabetes as a prognostic factor in the evolution of these patients was quantified.

Thus, a statistically significant difference was observed in terms of survival without disease progression. This difference is evident by following the Kaplan Meier curves between the groups of patients with / without type II diabetes. Statistical calculations performed for this group demonstrated a median progression-free survival of 24 months for patients not associated with diabetes $(n=39)$ compared to 15 months for diabetic patients $(\mathrm{n}=11)$. This difference is statistically significant $(p=0.04)$ thus establishing the role of the association of diabetic pathology in the evolution of breast cancer.

A paper published by Patterson R.E. and his collaborators reported a significant increase in mortality due to both breast cancer and all causes of mortality. These patients had a $26 \%$ higher risk of developing any event related to the progression of breast cancer compared to glycosylated hemoglobin below 6.5\% (23).

A pilot retrospective cohort study published by Yen-Lin Chang in 2017 showed that for each unit increase in the value of glycosylated hemoglobin, the risk of mortality from any cause but also from mortality specific to breast cancer is increased. Thus, if the level of glycosylated hemoglobin is kept below 7\%, the prognosis of patients with localized breast cancer is significantly improved (24).

These data from the literature support the results of this study, respectively, a decrease in survival without disease progression in patients associated with type II diabetes.

This retrospective study followed the evolution of a mixed group of patients in terms of diagnosis. Thus, the time to disease progression in patients with localized breast cancer was assessed compared to those diagnosed in the metastatic stage.

Patients who had metastases at the time of diagnosis have lower and median progression-free survival rates than patients without metastases $(\mathrm{p}<0.01)$.

In order to identify the prognostic factors involved in the evolution of breast cancer, continuous variables such as age, body mass index and proliferation index ki67 were also evaluated.

Although in the group of patients the mean value of body mass index was $28.76 \pm 4.81$ (D.S.) It could not be demonstrated that the body mass index influences survival without disease progression. Probably this fact is in the context of a significantly low number of normal-weight patients in this group, as well as the fact that in this study were included both patients in localized and metastatic stage.

Recent studies in the literature support the negative impact of obesity on the prognosis of breast cancer (25).

This retrospective study aimed to identify some prognostic factors involved in the evolution of breast cancer. We also tried to identify a correlation between the presence of excess adipose tissue and certain known prognostic factors such as the ki67 proliferation index.

The factors involved in the evolution of breast cancer that influenced the early progression of the disease were: the proliferation index ki67 $(\mathrm{p}<0.05)$, the presence of metastases at diagnosis $(p<0.0001)$ and the association of type II diabetes $(\mathrm{p}=0.0085)$. 
The limitations of this study are represented by its retrospective nature and the fact that in this study were included both patients diagnosed with early breast cancer and patients in metastatic stage.

\section{CONCLUSIONS}

When diagnosing a patient with breast cancer, the main question that arises is related to the means that could be used to improve the prognosis of these patients, both in the short and long term. In order to achieve this goal, we consider that the identification of prognostic factors that influence both the overall survival and the time to disease progression is an essential step.

The ki67 proliferation index was assessed in the group of patients analysed to assess the degree of aggression of breast tumours assessed in a group of patients in which overweight and obese patients predominated. Although in this group no correlation could be identified between the presence of excess adipose tissue and this index of proliferation, it seems that a percentage increase in the ki67 proliferation index is associated with a decrease in

Conflict of interest: none declared

Financial support: none declared

\section{REFERENCES}

1. http://gco.iarc.fr/obesity/tools-treemap.

2. WHO Global Health Observatory Data Repository [online database]. Geneva, World Health Organization, 2013. Available at: http://apps. who.int/gho/data/view.main.

3. Modesitt SC, van Nagell JR Jr. The impact of obesity on the incidence and treatment of gynecologic cancers: a review. Obstet Gynecol Surv. 2005 Oct;60(10):683-92.

4. Senkus E, Kyriakides S, Ohno S, Penault-Llorca F, Poortmans P, Rutgers E, Zackrisson S, Cardoso F; ESMO Guidelines Committee. Primary breast cancer: ESMO Clinical Practice Guidelines for diagnosis, treatment and follow-up. Ann Oncol. 2015 Sep;26 Suppl 5:v8-30.

5. Rojas MP, Telaro E, Russo A et al. Follow-up strategies for women treated for early breast cancer. Cochrane Database Syst Rev. 2005;CD001768.

6. Chlebowski RT, Aiello E, McTiernan A. Weight loss in breast cancer patient management. J Clin Oncol. 2002 Feb 15;20(4):1128-43.

7. Tampa M, Mitran Cl, Mitran MI, Nicolae I, Dumitru A, Matei C, Manolescu L, Popa GL, Caruntu C, Georgescu SR. The Role of Beta HPV Types and HPV-Associated Inflammatory Processes in Cutaneous Squamous Cell Carcinoma. J Immunol Res. 2020 Apr 6;2020:5701639.

8. Dragomirescu CC, Lixandru BE, Coldea IL, Corneli ON, Pana M, Palade AM, Cristea VC, Suciu I, Suciu G, Manolescu LSC, Popa LG, Popa MI. Antimicrobial Susceptibility Testing for Corynebacterium Species Isolated from Clinical Samples in Romania. Antibiotics (Basel). 2020 Jan 16;9(1):31.

9. Manolescu LSC, Boeru C, Căruntu C, Dragomirescu CC, Goldis M, Jugulete G, Marin M, Popa GL, Preda M, Radu MC, Popa MI. A Romanian experience of syphilis in pregnancy and childbirth. Midwifery. 2019;78:58-63.

10. Dragomirescu CC, Lixandru, BE, Coldea IL, Palade AM, Baltoiu M, Dinu S, Cristea VC, Manolescu L, Popa MI. Comparative analysis of different phenotypic and molecular methods used for the taxonomic time to disease progression. This could be the subject of further studies to identify the need to escalate treatments in these patients.

Another negative prognostic factor identified in this study is the association of type II diabetes, a factor that doubled the risk of early disease progression in these patients.

The molecular mechanisms by which diabetes, hyperglycaemia, hyperinsulinemia and metabolic changes related to these conditions interact with the proliferation of neoplastic cells and the evolution of breast cancer are the subject of numerous studies in the literature. Therefore, the impact that neglecting the control of type II diabetes in breast cancer patients may have adverse consequences for their survival. Early diagnosis and optimal treatment of diabetes is a controllable way to improve the prognosis of these patients.

Future prospective future studies could clarify the connection between breast cancer and metabolic syndrome and could lead to a personalization of therapeutic modalities as well as to the follow-up of these patients in multidisciplinary teams.

identification of Corynebacterium spp. isolated from clinical samples in Romania. Rom Biotechnological Lett. 2017;22(5):12926-33.

11. Manolescu L, Marinescu P. Sex differences in HIV-1 viral load and absolute CD4 cell count in long term survivors HIV-1 infected patients from Giurgiu, Romania. Romanian Review of Laboratory Medicine. 2013;21(2):217-24.

12. Marinescu P, Manolescu LSC. Association of hepatitis B infection in patients with HIV Encephalopathy. Romanian Biotechnological Letters. 2012.17(6):7817-24.

13. Manolescu L, Temereanca A, Diaconu CC, Ruta S. Correlation between resistance profile and immunosuppression in heavily treated HIV-1 infected Romanian patients. Romanian Biotechnological Letters. 2011.16 (4):6439-49.

14. Inwald EC, Klinkhammer-Schalke M, Hofstädter F, Zeman F, Koller M, Gerstenhauer M, Ortmann O. Ki-67 is a prognostic parameter in breast cancer patients: results of a large population-based cohort of a cancer registry. Breast Cancer Res Treat. 2013 Jun;139(2):539-52.

15. Niță I, Nițipir $C$, Toma Ș A, Limbău AM, Pîrvu E, Bădărău IA, et al. Histological Aspects and Quantitative Assessment of Ki67 as Prognostic Factors in Breast Cancer Patients: Result from a Single-Center, Cross Sectional Study. Medicina 2020;56(11):600.

16. Nattenmüller CJ, Kriegsmann M, Sookthai D, et al. Obesity as risk factor for subtypes of breast cancer: results from a prospective cohort study. BMC Cancer. 2018;18(1):616.

17. Cardoso F, Kyriakydes S, Penault-Llorca F, Poortmans P, Senkus E, Thompson A, Zackrisson S. Primary Breast Cancer ESMO Clinical Practice Guidelines. Ann Oncol. 2013;24(Suppl6):vi7-vi23.

18. Cardoso F, Senkus E, Costa A, Papadopoulos E, Aapro M, André F, Harbeck N, Aguilar Lopez B, Barrios CH, Bergh J, Biganzoli L, Boers-Doets CB, Cardoso MJ, Carey LA, Cortés J, Curigliano G, Diéras V, El Saghir NS, Eniu A, Fallowfield L, Francis PA, Gelmon K, Johnston SRD, Kaufman B, Koppikar S, Krop IE, Mayer M, Nakigudde G, Offersen BV, Ohno S, Pagani O, Paluch-Shimon S, 
Penault-Llorca F, Prat A, Rugo HS, Sledge GW, Spence D, Thomssen C, Vorobiof DA, Xu B, Norton L, Winer EP. 4th ESO-ESMO International Consensus Guidelines for Advanced Breast Cancer (ABC 4)†. Ann Oncol. 2018 Aug 1;29(8):1634-1657.

19. Pan H, Gray R, Braybrooke J, et al. 20 year-risks of breast-cancer recurrence after stopping endocrine therapy at 5 years. $N$ Engl $J$ Med. 2017;377(19):1836-1846.

20. Gianni L, Dafni U, Gelber RD, Azambuja E, Muehlbauer S, Goldhirsch A, Untch M, et al; Herceptin Adjuvant (HERA) Trial Study Team. Treatment with trastuzumab for 1 year after adjuvant chemotherapy in patients with HER2-positive early breast cancer: a 4-year follow-up of a randomised controlled trial. Lancet Oncol. 2011 Mar;12(3):236-44.

21. Kido Y, Nakae J, Accili D. Clinical review 125: The insulin receptor and its cellular targets. J Clin Endocrinol Metab. 2001 Mar;86(3):972-9.

22. Goodwin PJ, Ennis M, Pritchard KI, Trudeau ME, Koo J, Madarnas Y, Hartwick W, Hoffman B, Hood N. Fasting insulin and outcome in early-stage breast cancer: results of a prospective cohort study. J Clin Oncol. 2002 Jan 1;20(1):42-51.

23. Patterson RE, Flatt SW, Saquib N, Rock CL, Caan BJ, Parker BA, Laughlin GA, Erickson K, Thomson CA, Bardwell WA, Hajek RA, Pierce JP. Medical comorbidities predict mortality in women with a history of early stage breast cancer. Breast Cancer Res Treat. 2010 Aug;122(3):859-65.

24. Chang YL, Sheu WH, Lin SY, Liou WS. Good glycaemic control is associated with a better prognosis in breast cancer patients with type 2 diabetes mellitus. Clin Exp Med. 2018 Aug;18(3):383-390.

25. Copson ER, Cutress RI, Maishman T, Eccles BK, Gerty S, Stanton L, Altman DG, Durcan L, Wong C, Simmonds PD, Jones L, Eccles DM; POSH Study Steering Group. Obesity and the outcome of young breast cancer patients in the UK: the POSH study. Ann Oncol. 2015 Jan;26(1):101-112. 